\title{
Developing a Korean Version of the Scale for the Observation of Agitation in Persons with Dementia of Alzheimer-Type
}

\author{
Kim, Eun Young ${ }^{1} \cdot$ Lee, $\mathrm{Ye}^{-\mathrm{Na}^{2}} \cdot$ Jeong, Eunhye ${ }^{2} \cdot$ Chang, Sung $\mathrm{Ok}^{3}$ \\ ${ }^{1}$ Lecturer, Red Cross College of Nursing, Chung-Ang University, Seoul \\ ${ }^{2}$ Research Professor, College of Nursing, Korea University, Seoul \\ ${ }^{3}$ Professor, College of Nursing · BK21 FOUR R\&E Center for Learning Health Systems, Korea University, Seoul, Korea
}

\begin{abstract}
Purpose: The aim of this study was to develop a Korean version of the Scale for Observation of Agitation in Persons with Dementia of the Alzheimer-Type [DAT] (K-SOAPD) that reflects the Korean context of this problematic behavior and to evaluate its reliability and validity. Methods: This study was prepared based on the guidelines for translation and application of measurement scales presented by the World Health Organization. A total of 200 subjects from two nursing homes were included in this study. Exploratory factor and confirmatory factor analyses were performed to verify validity. Results: In the exploratory factor analysis (EFA), the K-SOAPD consisted of seven items with two factors: "physical movement" and "negative word". The K-SOAPD presented satisfactory validity and reliability (Cronbach's $\alpha=.86(p<.001)$, test-retest $=0.83(p<.001)$, inter-rater=.91 $(p<.001))$. This finding shows the $\mathrm{K}-\mathrm{SOAPD}$ is a valid and reliable scale for measuring agitation, the behavioral problem of dementia. Conclusion: This research can contribute toward establishing global standards by enabling international comparative studies of agitation among patients with dementia.
\end{abstract}

Key Words: Psychomotor agitation; Dementia; Alzheimer disease; Aged; Nursing homes

\section{INTRODUCTION}

The prevalence of dementia is steadily increasing as the world's elderly population grows, creating a serious problem worldwide [1]. Agitation is a major dementia-related behavior that is a challenge for caregivers to cope with [2], especially in long term care facilities [3]. Agitation is defined as "inappropriate verbal, vocal or motor activity, which is not an expression of unmet need, and encompasses physical and verbal aggression"[4]. Agitation is not a diagnostic term, but a term used by clinicians to indicate an individual's response to a symptom or behaviors that reflect a person's reaction to the care or their environment [5]. Agitation, which produces feelings of anger and helplessness, can negatively affect not only such patients, but also the quality of life (QOL) of their families and caregivers [6]. The incidence of agitation behavior varies slightly from study to study, but agitation behav- iors are observed in 83 to $96 \%$ of all long term care facility residents and in 56 to $98 \%$ of home- based patients with dementia living in communities [7]. Patients who display the symptoms of agitation with dementia can cause their caregivers and others around them severe distress [5]. Since agitation in dementia has many different etiologies and because people with agitation in dementia are often unable to accurately recall or report their experiences, a full and careful assessment is essential [5].

Korea is one of the world's most rapidly aging countries, $10.2 \%$ of the older adults over 65 were patients with dementia in 2017[8]. In Korea, as the population is aging, social hospitalization using nursing hospitals for the purpose of care is increasing, and the number of nursing hospitals is also increasing [9]. Dementia of Alzheimer-type accounts for the largest proportion in nursing hospitals from 2013 to 2019, and the resulting medical expenses, and the proportion is also constantly increasing [10].

\footnotetext{
Corresponding author: Chang, Sung Ok https://orcid.org/0000-0003-2710-4291

College of Nursing, Korea University, 145 Anam-ro, Seongbuk-gu, Seoul 02841, Korea.

Tel: +82-2-3290-4918, Fax: +82-2-928-9108, E-mail: sungok@korea.ac.kr
}

Received: Aug 12, 2020 / Revised: Oct 14, 2020 / Accepted: Nov 2, 2020

This is an open access article distributed under the terms of the Creative Commons Attribution Non-Commercial License (http://creativecommons.org/licenses/ by-nc/3.0), which permits unrestricted non-commercial use, distribution, and reproduction in any medium, provided the original work is properly cited. 
Therefore, in order to improve the quality of life and reduce the social cost of Alzheimer-type dementia patients in nursing hospitals, various studies about behavioral and psychological symptoms of dementia need to be conducted. Agitation is the most common behavioral and psychological symptom of dementia in Korea and it is recognized as one of the significant symptoms of dementia [10]. To reduce the behaviors associated with agitation in patients with dementia, intervention researches need to be conducted. However, in Korea, few studies have been conducted with the aim of reducing the agitation of patients with dementia. In addition, there is no Korean version of the scale that can measure agitation; thus, the introduction of such a scale, for which the reliability and validity have been verified, is a necessary first step. Development of a Korean version of the scale will also make it possible to compare foreign and Korean data, and, furthermore, it can contribute to international research collaboration. This could contribute to international research on agitation and ultimately contribute to the development of global standards.

The Scale for Observation of Agitation in Persons with Dementia of the Alzheimer-Type [DAT] (SOAPD) has a clearly defined concept and is patient-focused, psychometrically adequate, uncomplicated to apply in clinical settings, and, above all, easy to use from observers' perspectives $[11,12]$. In addition, its reliability and validity have been verified [11]. The SOAPD employs a Likert-type scoring scheme that consists of seven items to rate the duration and intensity of the agitation-related behavior. All seven items measure duration, while two measure intensity as well [11]. Despite these advantages, SOAPD has not yet been developed and used in several countries. If SOAPD is developed in various countries, in-depth studies on dementia patients can be carried out, and differences between countries can be understood. This study is expected to be the first step in international comparative research related to agitation.

The present study aimed to develop a Korean version of SOAPD that reflects the Korean context of this challenging behavior and to assess the reliability and validity of its conceptual properties.

\section{METHODS}

The aim of this study is to develop a Korean version of the Scale for Observation of Agitation in Persons with Dementia of the Alzheimer-Type (K-SOAPD) and to evaluate the reliability and validity of a K-SOAPD.

\section{Participant and Data Collection}

The participants were recruited from two nursing hospitals in P city, South Korea. The participants were 200 patients with dementia who voluntarily agreed to their involvement in the study. The number of participants was based on the criteria that the ratio of participants to variables was at least 5:1, and although the size of the sample required for factor analysis varies according to scholars, in an ideal case, the number of samples 200-300 is recommended, and for stable scale analysis, the number of samples 10 times the number of measurement items was recommended $[13,14]$. The inclusion criteria for participants were: 1) Patients who had been medically diagnosed with dementia, 2) were more than 20 years old, and 3) had lived in a nursing hospital for more than four weeks. Patients whose facial expressions were difficult to observe due to neurological injury and limited movement or limb paralysis were excluded because they determined that accurate measurements were difficult.

Since SOAPD is an assessment scale from an observer's point of view, for evaluating the scale, we selected nine nurses. The criteria for selecting nurses are as follows. 1) Those who are familiar with the characteristics of DAT and recommended by a nursing manager, 2) those who have worked in a nursing hospital for more than 3 years, 3) those who have agreed to the purpose of this study and voluntarily agreed to participate. The researchers first gave them an orientation, then trained them on the features and usage of the SOAPD for 60 minutes, and guided accurate usage individually. In addition, after checking the level of understanding of nurses through the question-and-answer time, they participated in data collection. The researcher discussed weekly progress by phone with the nurses. In addition, inter-rater reliability was checked to reduce errors in the measurement score between nurses who are measuring scales. Data collection was carried out from September 1 to November 15, 2019.

\section{Measurement}

\section{1) Scale to Observe Agitation in Persons with DAT (dementia of Alzheimer type) (SOAPD)}

The SOAPD [11] consists of seven items; four items measure body motion and three items measure noise. Each item measures duration, while two items simultaneously measure intensity. All of the items are scored on a five-point Likert scale from 1 to 5 . Higher scores mean longer duration and more strength, and lower scores reflect shorter duration and less strength. 


\section{2) Korean Version - Mini Mental State Examination (MMSE-K)}

MMSE-K is a scale used for the screening of dementia, MMSE was developed in 1975 by Folstein et al. [15] was standardized in Korean by Park and Kwon [16]. The total score can be measured from the lowest 0 points to the highest 30 points. The lower the score, the more severe the cognitive impairment, 0-17 points are obvious cognitive dysfunction, 18 23 points are mild cognitive impairment, and more than 24 points are considered normal.

In nursing hospitals where the subjects of this study were admitted, MMSE-K was evaluated twice a year based on the date of admission. Therefore, in this study, the recent measurement results of the study subjects were used.

\section{3) Korean instrumental activities of daily living (K-IADL)}

ADL is a scale to measure the activities of daily living, and the scale developed by Katz et al. [17] in 1963, and it was developed into a Korean version in 2002 by Won et al. [18]. Activities of daily living consists of a total of 7 items: getting dressed, washing your face, taking a bath, eating, moving, using the toilet, and adjusting your toilet. In the case of complete self-reliance, it is scored as 1 point, slightly assisted 2 points, and total assisted 3 points, and the total score is measured from the lowest 7 points to the highest 21 points. The higher the score, the higher the dependence on performing daily activities. Cronbach's $\alpha$ at the time of scale development was .94 [18]. Participating nursing hospitals in this study evaluated ADL once a month based on the admission date of the subject, and in this study, the results measured from September 1 to November 15, 2019 were used.

\section{4) Korean version of Cornell Scale for Depression in De- mentia (K-CSDD)}

CSDD was developed by Alexopoulos et al. [19] in 1988 and modified as Korean version by Lee et al. [20] in 2015. The K-CSDD [20] is a reliable and valid scale for measuring depression of dementia patients in long-term care facilities, and was used for convergence validity in this study. This scale consists of 19 items in five categories; the score for each question rages from 0 (absent) to 2 (severe), with a total score range of $0-38$. A higher score means a higher degree of depression, with a score of 18 or more indicating serious depression, a score of 10 or higher indicating severe depression, and a score of 8 or higher indicating depression.

\section{5) Korean Version of Quality of Life-Alzheimer's Disease scale (K-QOL-AD)}

K-QoL-AD was developed in 2002 by Logsdon et al. [21], and was developed in 2006 as a Korean version by Shin [22]. The K-QOL-AD [22], a reliable and valid scale to assess the quality of life (QOL) in the older adults with dementia, was used for discriminant validity. The K-QOL-AD consists of 13 items; the score for each question ranges from 1 (bad) to 4 (very good), with a total score of 13-52. A lower score means a lower QOL.

\section{Procedure}

The K-SOAPD was prepared based on the guidelines for translation and application of assessment scales presented by the World Health Organization [23]. Prior to conducting the research, we received approval for a Korean version of the agitation measurement scale from Hurley A.C., the main author of the original SOAPD scale.

\section{1) Translation and application of the scale}

First, the primary author of the study, whose native language is Korean, translated the English version of the scale into Korean. She has been a nurse in a general hospital and an expert on the older adults for more than five years. Second, the forward translation was reviewed by an expert fluent in both English and Korean. If inappropriate sections of the translation were found, the experts discussed them with the authors of the study. Third, it was translated back into English by a translator whose native language is English and who had no prior knowledge of the questionnaire. In addition, three nursing professors, a bilingual expert panel fluent in English and Korean, reviewed the equivalence and consistency of words, expressions, and translations in sentences, focusing on conceptual and cultural equivalence. The fourth step consisted of pre-testing and cognitive interviewing. We discussed the suitability and consistency of the questionnaire's contents with two long- term care nurses and one with a doctorate in nursing. As a result of those discussions, the translation was completed after all the subjects answered that the contents of the scale were appropriate and understandable. During this final phase, the content validity was verified by three professors of nursing. Using a five-point Likert scale, the content validity index was evaluated by whether the ratio of items that were given a score 4 (appropriate) or 5 (very appropriate) was more than $80 \%$. As a result of the verification, all seven items were scored 4 or 5 points, all items were selected and reflected in the final version of the scale, and the items of the K-SOAPD were confirmed. 


\section{2) Validation of the scale}

Before the data collection, a pretest was conducted with the seven participants. After the evaluation of the pretest, the final items were completed and we distributed it to the participants.

For evaluating the K-SOAPD, the validity was verified by item analysis, exploratory factor analysis and confirmatory factor analysis. And we performed convergent, discriminant, and criterion validity. In addition, discriminant validity between the K-SOAPD and the existing scales (K-QOL-AD and K-CSDD) was conducted. The reliability of this scale was validated through internal consistency, test-retest reliability and inter-rater reliability.

\section{Data Analysis}

The collected data were analyzed using the SPSS/WIN 25.0, AMOS 26.0 program. The demographic characteristics of the subjects were presented as frequency, percentage, mean, and standard deviation. In order to verify the homogeneity of the items constituting the scale, the item-total correlation (ITC) was analyzed.

Exploratory factor analysis (EFA) was performed to verify the relationship between sub-concepts. Prior to exploratory factor analysis, Kaiser-Meyer-Olkin (KMO) and Bartlett spherical tests were performed to confirm the suitability of the factor analysis. EFA was performed using a principal axis factor analysis with varimax rotation on the data from the general population sample.

To verify the fit of the proposed model, Confirmatory Factor Analysis (CFA) was performed. $x^{2}$ statistics, Root Mean Square Error of Approximation (RMSEA), Normed Fit Index (NFI), Incremental Fix Index (IFI), Turker-Lewis Index (TLI), Comparative Fit Index (CFI), Goodness of Fit Index (GFI), and Adjusted Goodness-of-Fit-Index (AGFI) were determined by structure equation model analysis. To test the K-SOAPD's criterion validity, averaged variance extracted (AVE) and construct reliability (CR) analysis were carried out. For verifying the discriminant validity of the K-SOAPD, the squared value of the correlation coefficient between the mean variance extracted value and the factors were compared. The reliability of the K-SOAPD was verified by Cronbach's $\alpha$ and test-retest.

\section{Ethical Considerations}

The study was approved by the Ethical Committee of the Korea University [KU-IRB-18-22-A-2-(E-A-1) (R-A-1)]. The research project for the development of 5 types of the Korean version of the symptoms evaluation for patients with dementia was approved by the university's IRB, and this study was conducted as part of it. All participants provided written informed consent.

Prior to collecting the data, the researcher explained the purpose and procedure of the study to the head of the nursing institution via official letter or phone, and then received approval for recruitment. Research was conducted after receiving consent for personal information from the subject or legal representative in advance.

In order to ensure the autonomy of participation in the research, when recruiting research subjects, the purpose and procedure of this study was orally explained to the subjects deemed appropriate, and a copy of the consent was provided to the research participants after receiving written consent for the subjects who indicated their intention to participate in the research.

In this study, out of 200 subjects diagnosed with dementia, 193 people who had difficulty in communication received consent from their legal representative for participation in the study. It was explained that the research subject (legal representative) has the right to refuse to participate or to withdraw in the middle, and there is no penalty for this. The subject information collected for this study is not used for purposes other than the study, and the personal information of the study participants was kept confidential even after the study was completed.

In addition, the scale evaluator was nine nurse in a nursing hospital, the purpose of the study was fully explained to nurses before data collection, and written consent was received from nurses who voluntarily decided to participate. To ensure the confidentiality of the contents of the response, the questionnaire was immediately sealed. Patients were provided with rewards after data collection, and nurses were rewarded according to the number of evaluation questionnaires.

\section{RESULTS}

\section{General Characteristics of Subjects}

A total of 200 subjects participated, 144 females (72.0\%) and 56 males $(28.0 \%)$. Their mean age was 83.1 years (49 97 years). A total of 185 patients (92.5\%) had at least one comorbidity other than Alzheimer's disease, and 29 patients $(14.5 \%)$ had more than three comorbidities. Among them, hypertension was the most common, 99 patients $(49.5 \%)$, and diabetes was the second most common, 33 patients (16.5\%). The average Mini Mental State Examination (MMSE) score, aimed at identifying and measuring impairment of cognitive function, was 9.37 out of 30; the 
average Activities of Daily Living (ADL) score, aimed at measuring the level of basic movements in daily life, was 17.07. The average K-SOAPD score was 4.10 out of 15 (Table 1).

Table 1. General Characteristics of the Participants $(N=200)$

\begin{tabular}{llrr}
\hline Characteristics & Categories & $\mathrm{n}(\%)$ & $\mathrm{M} \pm \mathrm{SD}$ \\
\hline Age (year) & $40 \sim 49$ & $1(0.5)$ & $83.1 \pm 8.20$ \\
& $50 \sim 59$ & $3(1.5)$ & \\
& $60 \sim 69$ & $10(5.0)$ & \\
& $70 \sim 79$ & $40(20.0)$ & \\
& $\geq 80$ & $146(73.0)$ & \\
Gender & Female & $144(72.0)$ & \\
& Male & $56(28.0)$ & \\
MMSE (30) & $0 \sim \leq 23(\mathrm{CI})$ & $200(100.0)$ & $9.37 \pm 2.64$ \\
ADL (21) & & & $17.07 \pm 4.15$ \\
Comorbidities & 0 & $15(7.5)$ & \\
& $1 \sim 2$ & $156(78.0)$ & \\
& $\geq 3$ & $29(14.5)$ & \\
K-SOAPD (15) & & & $4.10 \pm 3.58$ \\
\hline
\end{tabular}

$\mathrm{ADL}=$ Activities of daily living; $\mathrm{CI}=$ Cognitive impairment; K-SOAPD= Korean version of the Scale for the Observation of Agitation in Persons with Dementia of Alzheimer-Type; MMSE=Mini mental state examination; $\mathrm{M}=\mathrm{Mean} ; \mathrm{SD}=\mathrm{Standard}$ deviation.

The average age of the nurse participants was 39.7 years old (range: 33 46 years). Among them, three nurses graduated nursing college degree, four graduated university, and two had Master's degree. The average period of hospital experience before going to work in a nursing hospital was 10 years and 4 months. The average period of experience in a nursing hospital was 6 years and 3 months.

\section{Item Analysis}

Skewness values (0.90 2.18) and kurtosis values (-0.76 4.91) show this result is a normal distribution. If item-total correlation is less than .4, it is judged to have little contribution to the construction of the scale and is excluded. Since the item-total correlation ranged from .46 to .64, no items were removed (Table 2).

\section{Construct Validity}

In order to evaluate construct validity, an EFA was conducted on the data from the K-SOAPD. The KaiserMeyer-Olkin value was .79, and Bartlett's chi-squared test of sphericity $\left(x^{2}=398.36, \mathrm{df}=21, p<.001\right)$ was significant. Therefore, the suitability of the factor analysis in this study was verified. A principal factor analysis with verimax rotation was also conducted. Principal component analysis is carried out to extract fewer factors while minimizing information loss. Verimax rotation is an orthogonal rotation that is used when no correlation between factors is assumed (Table 2).

The criteria for proper factor extraction are an eigenvalue of 1.0 and a factor load of more than \pm .40 [24]. Factor analysis for the seven items found that factors with eigenvalues greater than 1.0 were extracted from both factors. No items had a factor loading of less than .40. Factor loadings ranged from .65 to .89 , and all seven items were considered important. Therefore, all seven items were included in the analysis. Factor 1 was extracted from four items and is the most important factor, explaining $33.2 \%$ of the total variance. The item with the largest factor loading was "repetitive movement in place" Factor 1 was named "physical movement". Factor 2 accounted for $30.1 \%$ of the total variance and consisted of three items. The item with the largest factor loading was "negative words" Factor 2 was named "verbal sound” (Table 2).

\section{Confirmatory Factor Analysis (CFA)}

To verify the convergent validity and discriminant validity of the K-SOAPD identified by EFA, a confirmatory factor analysis (CFA) was performed with the data used in the EFA. The model fit index of the CFA presented a RMSEA value of .08, NFI .93, TLI .90, CFI .95, RFI .84, Delta2 IFI .96, and CMIN/DF 2.36. As the result of the analysis of the model fit, it was considered appropriate (Table 2).

\section{Convergent Validity and Discriminant Validity}

The convergent validity was carried out by analysis of the AVE and the CR to identify that the extracted factors measured the concepts consistently. As the factors of the K-SOAPD were presented to be higher than AVE 0.5 and CR 0.7 , the convergent validity was verified (Table 2 ).

\section{Criterion Validity}

The criterion validity was validated by assessing the correlation between the K-SOAPD and the K-CSDD. Between the two scales, the correlation was statistically significant $(\mathrm{r}=.53, p<.001)$ (Table 3$)$. 


\section{Discriminant Validity between the K-SOAPD and the Existing Scale}

The K-QOL-AD was used to test the discriminant validity between the K-SOAPD and the existing scale. The K-QOL-AD was found to be inversely correlated with the K-SOAPD and to be statistically significant $(\mathrm{r}=-.47, p<.001)$ (Table 3).

\section{Reliability}

The Cronbach's $\alpha$ of the K-SOAPD was .86. For factor 1 , "physical movement", the Cronbach's $\alpha$ was .84 and for factor 2, "verbal sound", it was .83. Test-retest reliability was used to verify the stability of the K-SOAPD. The second data collection was conducted two weeks after the first data collection. As the minimum required sample size for a paired t-test is 30 [25] and considering that at least twice as many samples as items are required [26], 40 out of 200 subjects were selected to participate. As a result of the test-retest correlation, the stability of the K-SOAPD was validated with $.83(p<.001)$. In addition, the inter-rater reliability to see whether the same subjects were evaluated consistently among the evaluators was to have one subject evaluated by two nurses as a pair. The data of 40 nurses in two nursing hospitals who responded without omission to all items were analyzed. As a result of the inter-rater correlation was .91 $(p<.001)$, which was found to be consistent.

\section{DISCUSSION}

This study was conducted to develop a Korean version of the SOAPD which can measure the degree of agitation

Table 2. Item Distribution Characteristics, Exploratory Factor Structure, and Internal Consistency of the K-SOAPD (N=200)

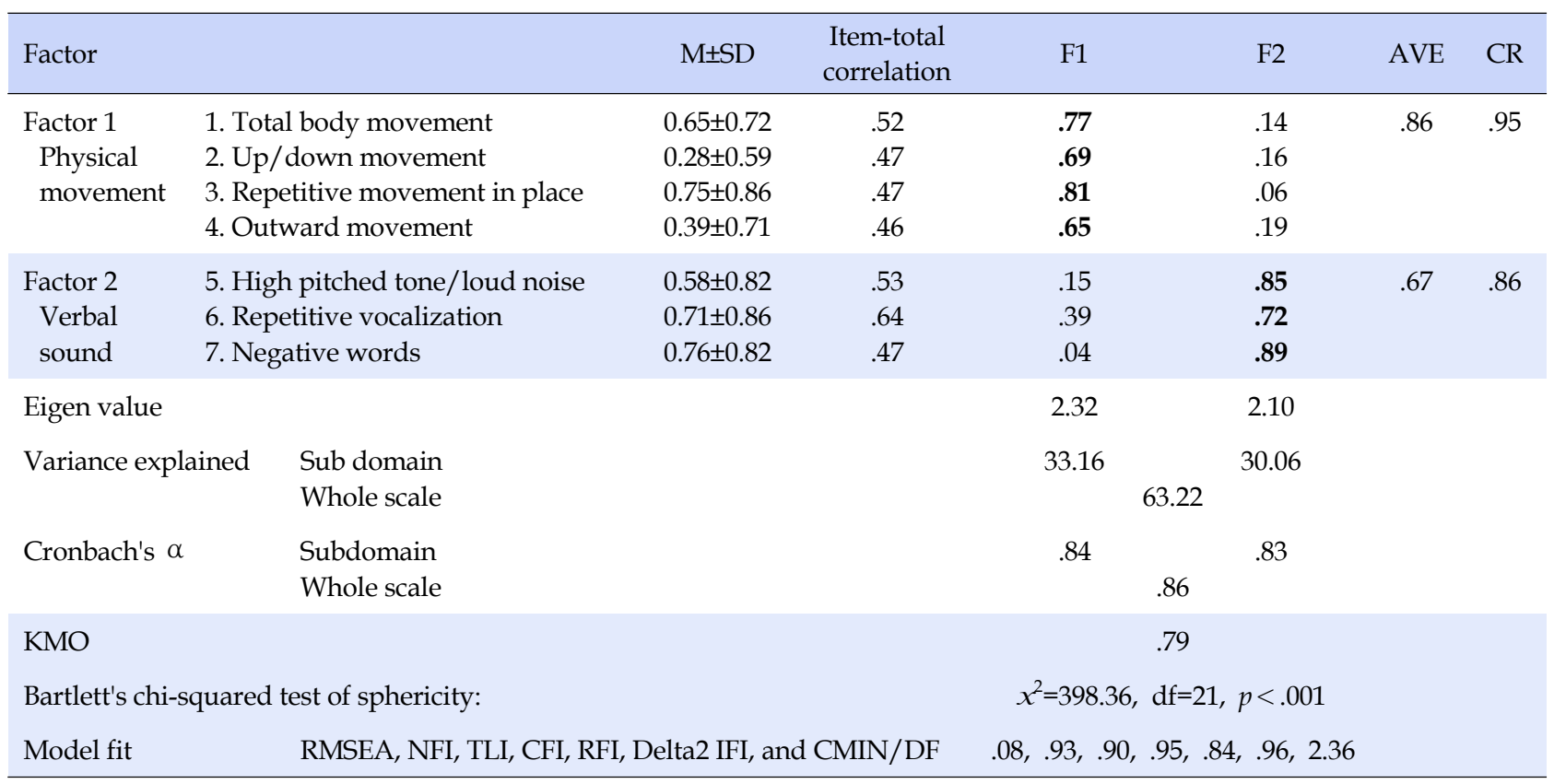

$\mathrm{AVE}=$ Averaged variance extracted; $\mathrm{CFI}=$ Comparative fit index; $\mathrm{CR}=$ Construct reliability; $\mathrm{CMIN} / \mathrm{DF}=$ Minimum chi-square/Degree of freedom; IFI=Incremental fix index; KMO=Kaiser-Meyer-Olkin; $\mathrm{df}=$ Degree of freedom; K-SOAPD=Korean version of the Scale for Observation of Agitation in Persons with Dementia of the Alzheimer-Type; M=Mean; NFI=Normed fit index; RFI=Relative fit Index; RMSEA=Root mean square error of approximation; TLI=Turker-Lewis index; $\mathrm{SD}=\mathrm{Standard}$ deviation.

Table 3. Correlation with K-QOL-AD, K-CDSS, and Test-Retest Reliability

\begin{tabular}{|c|c|c|c|c|}
\hline \multirow{2}{*}{ Variables } & K-QOL-AD & K-CSDD & Test-retest reliability & Inter-rater reliability \\
\hline & $\mathrm{r}(p)$ & $\mathrm{r}(p)$ & $\mathrm{r}(p)$ & $\mathrm{r}(p)$ \\
\hline K-SOAPD & $-.47(<.001)$ & $.53(<.001)$ & $.83(<.001)$ & $.91(<.001)$ \\
\hline
\end{tabular}

$\mathrm{K}-\mathrm{QOL}-\mathrm{AD}=$ Korean version of quality of life-Alzheimer's disease scale; K-CSDD : Korean version of Cornell scale for depression in dementia; K-SOAPD=Korean version of scale for the observation of agitation in persons with dementia of Alzheimer-type. 
of dementia of Alzheimer type patients and to evaluate its reliability and validity as a basis for studying the development of interventions against such agitation. SOAPD is composed of 7 items and has the advantage of being a simple and easy to use. Moreover, it is a reliable measurement scale with evaluation reliability and validity. In addition, since the intensity of movement is reflected, it can be said that it is a scale that reflects the characteristics of agitation well. Despite these advantages, SOAPD has not yet been developed and used in several countries. If SOAPD is developed in various countries, in-depth studies on dementia patients can be carried out, and differences between countries can be understood. This study is expected not only to be used as a basic data for activating agitation behavior research in domestic dementia patients, but also as the first step in international comparative studies related to agitation.

The Cronbach's $\alpha$ of K-SOAPD was .86, which is higher than that of the original SOAPD (Cronbach's $\alpha=.70$ ), demonstrating that the K-SOAPD has high internal consistency. Our study attempted to validate the scale's reliability and validity in multiple ways by using EFA and CFA.

In the EFA, the two factors that were extracted were "physical movement" and "verbal sound". This was similar to the original SOAPD, which is divided into physical agitation and vocal agitation. Factor 1, "physical movement", signifies that a patient repeats some meaningless movement and for how long. Factor 2 represents repetitive and continually repeated meaningless language or sounds. These factors comprehensively include the observable symptoms of agitation. The highest factor loading in factor 1, "physical movement" was "repetitive movement in place", which had a factor loading of .81 and was the item that best explained factor 1 , "physical movement". The highest factor loading in factor 2, "verbal sound" was "negative words" with a factor loading of .89. All seven items appear to have high factor loadings of .65 .89 and all item-total correlations were over .40 , indicating that the seven items are well organized.

In the CFA, model fit was found to be mostly appropriate and excellent, and the convergent validity and discriminant validity of the two factors were also tested. This is a result that supports that the K-SOAPD measures the concept well.

In the criterion validity and discriminant validity between the K-SOAPD and the existing scale, this study showed that the correlation coefficient with K-CSDD was $.53(p<.001)$, which was significantly high. In terms of construct validity, the correlation coefficient with K-QOL
-AD was -.47 $(p<.001)$, indicating a low correlation, and the discriminant validity was verified. Cronbach's $\alpha$ coefficient, which is the internal reliability coefficient of this study, was relatively high (.86), and internal reliability was tested, with the test-retest reliability test results showing a correlation of $.83(p<.001)$. In this case, the stability of the scale was also verified by satisfying the criteria for a stable scale [27].

In this study, we determined that the agitation symptoms of DAT patients were associated with two behavioral factors, physical movement and verbal sound. This is consistent with a previous study [2] that reported that agitation is one of the behaviors of patients with dementia that most challenges caregivers, one characterized by physical and verbal behaviors. The advantages of this scale are that it is patient focused, conceptually distinct from related concepts, psychometrically adequate, and uncomplicated to administer in clinical settings [11].

In Algae's need-driven dementia-compromised behaviors (NDB) model [28], it was suggested that agitation of patients with dementia ultimately manifests as unsatisfied needs, which are divided into background factors and proximity factors. Background factors refer to personal characteristics that do not change relatively, and proximity factors refer to factors that are likely to change depending on the situation. Agitation is included in the proximity factor, which shows physical and verbal characteristics, consistent with our findings. This NDB model suggests that satisfying these unmet needs is an important part of nursing intervention. Measuring agitation, one of the factors affecting unmet needs in patients with dementia, is more than just evaluating a symptom. Measurement of agitation can ultimately be the basis for developing nursing interventions. This could be the basic data for various studies for the wellness of Alzheimer's type dementia patients, which account for the largest proportion in nursing hospitals. In addition, it can ultimately help to decrease behavioral and psychological symptoms of dementia and reduce the social costs of hospitalization in nursing hospitals. Especially in Korea, where older adults and patients with dementia are rapidly increasing, the establishment of basic data must be the basis for improving the QOL of patients with dementia.

Among the participants, $73 \%$ were over the age of 80 while only $2 \%$ were under 60 ; participants of various ages were not recruited. However, considering that most patients with dementia are older adults, the sample can be considered acceptable. In addition, all the subjects in this study had low cognitive function, with scores of 23 or less on the MMSE. It is suggested that further studies on dif- 
ferences in the severity of agitation according to the degree of cognitive function be performed.

\section{Limitations}

Due to the relatively small number of subjects, EFA and CFA were performed on the same subjects. Devellis noted that the pattern of factors from a large number of subjects was more stable, suggesting that the number of subjects required for scale development with EFA and CFA be 300 or more each [14]. However, even if the same data are used for EFA and CFA, results analysis based on expert opinion or existing research theory after factor analysis is important [29] and some previous literature suggests that good results can be obtained even with small sample sizes when high loading values are measured [30]. In addition, there are various sample size criteria such as the criteria used in this study, thus despite the relatively small number of subjects in this study, it could be considered that high quality results were obtained. Considering the limitation of this study, it could be suggested that further study is needed to secure more sites and participants for research and re-test the reliability and validity of this study through repeated studies.

\section{CONCLUSION}

Agitation is a significant problem behavior of patients with dementia, the measurement of agitation may be the basis for the development of various interventions to reduce this problem. And this could promote to develop a global standard for the difficult behaviors of patients with dementia. In addition, the development of measurement scales in various countries will enable comparative research between them and help to form a global standard for the difficult behaviors of patients with dementia.

\section{CONFLICTS OF INTEREST}

The authors declared no conflict of interest.

\section{AUTHORSHIP}

Study conception and design acquisition - CSO; Data collection - , KEY, LY-N, JE and CSO; Analysis and interpretation of the data KEY and CSO; Drafting and critical revision of the manuscript KEY and CSO; Final Approval - CSO.

\section{ACKNOWLEDGEMENT}

This research was supported by Basic Science Research Program through the National Research Foundation of Korea (NRF) funded by the Ministry of Education, Science and Technology (NRF-

\section{R1A2B4007896) (NRF-2019R1A2C1086122).}

\section{REFERENCES}

1. Weller J, Budson A. Current understanding of Alzheimer's disease diagnosis and treatment. F1000Research. 2018;7(1161): 1-9. https://doi.org/10.12688/f1000research.14506.1

2. Gang MS, Park HO, Park HJ. Factors affecting agitation in nursing home patients with dementia. Journal of Korean Gerontological Nursing. 2016;18(1):41-52. https://doi.org/10.17079/jkgn.2016.18.1.41

3. Livingston PG, Sommerland A, Orgeta V, Costafreda SG, Huntley J, Ames D, et al. Dementia prevention, intervention, and care. The Lancet. 2017;390(10113):2673-734.

https://doi.org/10.1016/S0140-6736(17)31363-6

4. Cohen-Mansfield J, Billig N. Agitated behaviors in the elderly: I. A conceptual review. Journal of the American Geriatrics Society. 1986;34(10):711-21. https://doi.org/10.1111/j.1532-5415.1986.tb04302.x

5. Griffiths AW, Albertyn CP, Burnley NL, Creese B, Walwyn R, Holloway I, et al. Validation of the Cohen-Mansfield Agitation Inventory Observational (CMAI-O) tool - ERRATUM. International Psychogeriatrics. 2020;32(1):75-85.

https://doi.org/10.1017/S104161021900053X

6. Livingston G, Barber J, Rapaport P, Knapp M, Griffin M, King $\mathrm{D}$, et al. Long-term clinical and cost-effectiveness of psychological intervention for family carers of people with dementia: a single-blind, randomized, controlled trial. The Lancet Psychiatry. 2014;1(7):539-48. https://doi.org/10.1016/S2215-0366(14)00073-X

7. Cerejeira J, Lagarto L, Mukaetova-Ladinska EB. Behavioral and psychological symptoms of dementia. Frontiers in Neurology. 2012;3(73):1-21. https://doi.org/10.3389/fneur.2012.00073

8. Joong-Ang Dementia Center. Korean dementia observatory 2018 [Internet]. Seoul: Joong-Ang Dementia Center; 2019 [updated 2019 Mar 29; cited 2020 Apr 20]. Available from: https://www.nid.or.kr/info/dataroom_view.aspx?bid=194

9. Health Insurance Review \& Assessment Service. Key statistics for medical expenses in 2019 [Internet]. Won-ju: Health Insurance Review \& Assessment Service; 2019 [updated 2019 Mar 29; cited 2020 Sep 14]. Available from:

https://www.hira.or.kr/bbsDummy.do?pgmid=HIRAA020 045010000\&brdScnBltNo=4\&brdBltNo=2329\&pageIndex $=1 \#$ none

10. Lee KS, Kim SH, Hwang HJ. Behavioral and psychological symptoms of dementia and antipsychotic drug use in the elderly with dementia in Korean long-term care facilities. DrugsReal World Outcomes. 2015;2(4):363-8. https://doi.org/10.1007/s40801-015-0047-0

11. Hurley AC, Volicer L, Camberg L, Ashely J, Woods P, Mc- 
Intyre K, et al. Measurement of observed agitation in patients with dementia of the Alzheimer type. Journal of Mental Health and Aging. 1999;5(2):117-33.

12. Volicer L, van der Steen JT. Outcome measures for dementia in the advanced stage and at the end of life. Advanced in Geriatrics. 2014; Article ID 346485:1-10. https://doi.org/10.1155/2014/346485

13. Tabachnick BG, Fidell LS. Using multivariate statistics. 5th ed. Boston, MA: Pearson/Allyn \& Bacon; 2007.

14. DeVellis RF. Scale development: theory and applications. 4th ed. Thousand Oaks, CA: Sage Publications; 2017.

15. Folstein MF, Foltein SE, McHugh PR. "Mini-mental state”. A practical method for grading the cognitive state of patients for the Clinican. Journal of Psychiatric Research. 1975;12(3):189-98. https://doi.org/10.1016/0022-3956(75)90026-6

16. Park J, Kwon Y. Standardization of Korean version of MiniMental State Examination (MMSE-K) for use in the elderly. Part II. diagnosis validity. Journal of the Korean Neuropsychiatric Association. 1989;28(3):508-13.

17. Katz S, Ford AB, Moskowitz RW, Jackson BA, Jaffe MW. Studies of illness in the aged: the index of ADL, a standard measure of biological and psychosocial function. JAMA. 1963;185 (12):914-9. https://doi.org/10.1001/jama.1963.03060120024016

18. Won CW, Rho YG, Sunwoo D, Lee YS. The validity and reliability of Korean Instrumental Activities of Daily Living (K-IADL) scale. Journal of the Korean Geriatrics Society. 2002; 6(4):273-80.

19. Alexopoulos GS, Abrams RC, Young RC, Shamoian CA. Cornell scale for depression in dementia. Biological Psychiatry. 1988;23(3):271-84. https://doi.org/10.1016/0006-3223(88)90038-8

20. Lee Y, Lee YS, Hong GRS. Validation of Korean version of the Cornell scale for depression in dementia among older adults in long-term care facilities. Journal of Korean Gerontological Nursing. 2015;17(3):142-51. https://doi.org/10.17079/jkgn.2015.17.3.142

21. Logsdon RG, Gibbons LE, McCurry SM, Teri L. Assessing quality of life in older adults with cognitive impairment. Psy- chosomatic Medicine. 2002;64(3):510-9.

https://doi.org/10.1097/00006842-200205000-00016

22. Shin HY. A preliminary study on the Korean version of Quality of Life-Alzheimer's Disease (QoL-AD) scale in community dwelling elderly with dementia. Journal of Preventive Medicine and Public Health. 2006;39(3):243-8.

23. World Health Organization. Process of translation and adaptation of instruments [Internet]. Geneva: World Health Organization; 2016 [updated 2016; cited 2020 Mar 15]. Available from: https://www.who.int/substance_abuse/research_tools/trans lation/en/

24. Song GJ. SPSS/AMOS statistical analysis method. Revision ed. Paju: 21cbook; 2016.

25. Cohen-Mansfield J, Werner P, Marx MS. An observational study of agitation in agitated nursing home residents. International Psychogeriatrics. 1989;1(2):153-65. https://doi.org/10.1017/s1041610289000165

26. Cho MS, Lee SK. Development of measurement scale for Korean Scaling Fear-1.0 and related factors. Journal of Dental Hygiene Science. 2009;9(3):327-38.

27. DeVon HA, Block ME, Moyle-Wright P, Ernst DM, Hayden SJ, Lazzara DJ, et al. A psychometric toolbox for testing validity and reliability. Journal of Nursing Scholarship. 2007;39(2): 155-64. https://doi.org/10.1111/j.1547-5069.2007.00161.x

28. Algae DL, Beck D, Kolanowski A, Whall A, Berent S, Richards $\mathrm{K}$, et al. Need-driven dementia-compromised behavior: an alternative view of disruptive behavior. American Journal of Alzheimer's Disease. 1996;11(6):10-9. https://doi.org/10.1177/153331759601100603

29. Choi CH, You YY. The study on the comparative analysis of EFA and CFA. The Society of Digital Policy and Management. 2017;15(10):103-11. https://doi.org/10.14400/JDC.2017.15.10.103

30. Kang H. A guide on the use of factor analysis in the assessment of construct validity. Journal of Korean Academy of Nursing. 2013;43(5):587-94.

https://doi.org/10.4040/jkan.2013.43.5.587 
Appendix 1. 최종 한국어 버전 치매환자 초조 측정 도구

대상자 이름:

날짜:

Korean version of the Scale for the Observation of Agitation in Persons with Dementia of Alzheimer-Type

\begin{tabular}{|c|c|c|c|c|c|c|c|c|c|c|c|}
\hline \multirow[b]{2}{*}{ 항목 } & \multicolumn{4}{|c|}{ 지속기간 } & \multirow[b]{2}{*}{ 비고 } & \multicolumn{4}{|c|}{ 강도 } & \multicolumn{2}{|c|}{ 점수 } \\
\hline & 없음 & 짧게 & 중간 & 길게 & & 없음 & 약하게 & 중간 & $\begin{array}{c}\text { 매우 } \\
\text { 강하게 }\end{array}$ & 지속기간 & 강도 \\
\hline 1. 몸 전체 움직임 & 0 & 1 & 2 & 3 & & & & & & & \\
\hline 2. 위/아래 움직임 & 0 & 1 & 2 & 3 & & & & & & & \\
\hline 3. 제자리에서의 반복적인 몸동작 & 0 & 1 & 2 & 3 & & 0 & 1 & 2 & 3 & & \\
\hline 4. 밖으로 향하는 움직임 & 0 & 1 & 2 & 3 & & 0 & 1 & 2 & 3 & & \\
\hline 5. 고음 또는 시끄러운 소음 & 0 & 1 & 2 & 3 & & & & & & & \\
\hline 6. 반복적인 소리 & 0 & 1 & 2 & 3 & & & & & & & \\
\hline 7. 부정적 단어 & 0 & 1 & 2 & 3 & & & & & & & \\
\hline
\end{tabular}

짤게 < 16 seconds,

16 seconds $\leq$ 중간 $<2.5$ minutes

2.5 minutes $\leq$ 길게 $<5$ minutes. 